\title{
The Specific Identification of Fæcal Pellets.
}

\author{
By \\ Hilary B. Moore, B.Sc., \\ Assistant Naturalist at the Marine Station, Millport.
}

With 6 Figures in the Text.

In fine muds such as those covering most of the bottom in the deeper parts of the Clyde Sea Area the formation of fæcal pellets is a factor of great biological importance. In these muds up to 40 per cent of the fine material is often consolidated into fæcal masses, and in extreme cases even the whole of the mud may be in the form of pellets. The significance of this process is clear. In the first place, the effective particle size of a large proportion of the mud is very greatly increased, and this in turn affects such characters as the porosity of the bottom, and the liability of the material to be transported by currents. In the second place, among selective feeders such as Syndosmya alba, which feed on the mud, there is an economy of labour, in that food which has once passed through the gut is set aside in a form in which it will be refused if again taken in by the siphons. This latter process can readily be seen in the example cited whose rejecta on examination prove to be almost entirely composed of pellets of its own and other species.

The object of the present paper is to show the possibility of distinguishing between the various types of pellet occurring on any given ground. While it would be impossible to give a key distinguishing between all the types of pellets occurring in nature, it is probable that this may be done for any individual locality where the number of dominant species present is not too great. The locality chosen-St. 11- lies in a depth of 73 metres in Loch Striven, and is a very sheltered area with a soft mud bottom. The general nature of the mud here, as well as the fauna, is discussed in other papers (Moore, 4 and $\mathbf{5}$ ).

Many mud-dwelling species, such as Syndosmya alba (Fig. 1), Nucula spp. and various polychætes, form pellets of very precise and unvarying shape. Others like Syndosmya nitida (Fig. 2) show much less regularity, while a few such as Axinus flexuosus void their fæces with no definite form. The majority of the important mud-dwelling species, however, form pellets, and these are surprisingly solid and resistant; they will stand fairly rough handling, and can even be boiled with sulphuric acid 


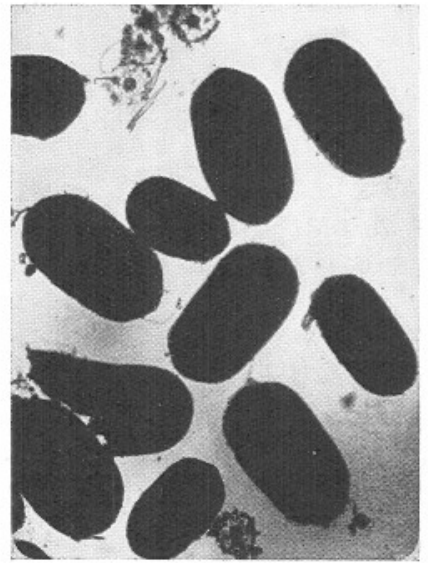

Frg. 1.-Pellets of Syndosmya alba, $\times 60$.

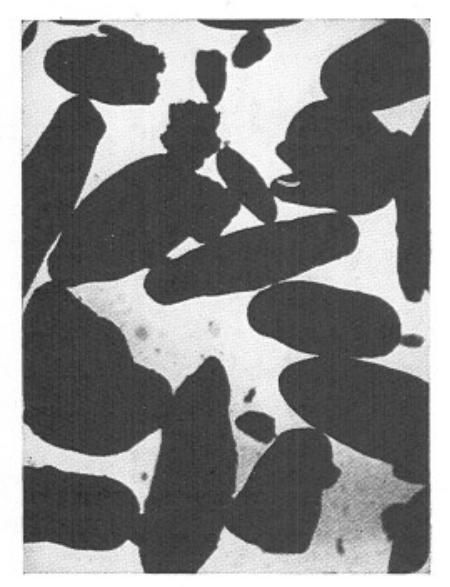

FIG. 2.--Pellets of Syndosmya nitida, $\times 36$.



Fig. 3.-Pellets of Nucula nucleus. 
or strong caustic soda without breaking down. On the other hand, the pellets of some of the planktonic forms such as Calanus, though quite definite in form, are much more easily destroyed, and are consequently not often identified except on the extreme surface of the mud.

The pellets have been examined both by collecting those shed by animals while under observation, and also by clearing the rectum in oil, or - as in the case of Nucula-by embedding the rectum in paraffin wax, and sectioning it. Except where stated, the following descriptions are the result of the examination of a number of specimens. There is a suggestion in the case of forms such as Calanus and Euphausids that the nature of the pellets may depend to some extent on the type of food which has been eaten. Dodgson (1) has found variation in the colour of the fæces of Mytilus edulis according to the nature of the food. The following are the chief types distinguishable on this station.

Nucula. The pellets of Nucula are voided in the form of a long rod of compact mud which breaks into lengths of $0 \cdot 2$ to $1.0 \mathrm{~mm}$. or more, the breadth being about $0.15 \mathrm{~mm}$. in pellets from an individual $1 \mathrm{~cm}$. long. The intestine of Nucula shows thickened longitudinal ridges with long cilia, and these form grooves in the smooth surface of the pellet, whose number and position vary according to the species (Fig. 3). These pellets are sufficiently firm to allow identification in muds laid down on the bottom for over fifty years (Moore, 5).

Nucula tenuis. Fig. 4, A.

Five very prominent equal longitudinal ridges; all the grooves are deeply cut, and the ventral pair are the most open.

Nucula nitidx. Fig. 4, B.

Seven longitudinal ridges, the ventral one being smaller and sunk between the two on either side; none of the grooves are deeply cut, and in a rubbed or dirty pellet they may appear to be absent.

Nucula nitida*_radiate form. Fig. 4, C.

Only five longitudinal ridges, but they are of the nitida type, with the lateral and ventro-lateral ridges fused to form one broad ridge; the grooves are shallow and the ventral ridge slightly sunk as in N. nitida.

Nucula nucleus and N. radiata. Fig. 4, D and F; and Fig. 3.

Seven longitudinal ridges as in $N$. nitida, but more prominent and with the grooves more deeply cut-sometimes more deeply than shown in the figure and even so much so as to allow the ridges to be split off separately.

* This form is distinct from N. radiata, but also according to its pellets distinct from N. nitida. I am indebted to Mr. R. Winkworth for its identification. 
Fig. 4, F, shows diagrammatically the position of the grooves as seen in surface view, but identification of all these forms is easier by examination of the ends.

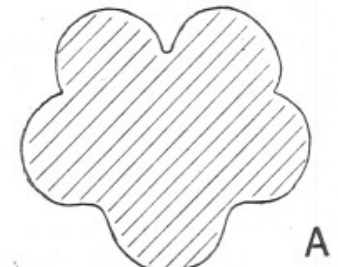

A
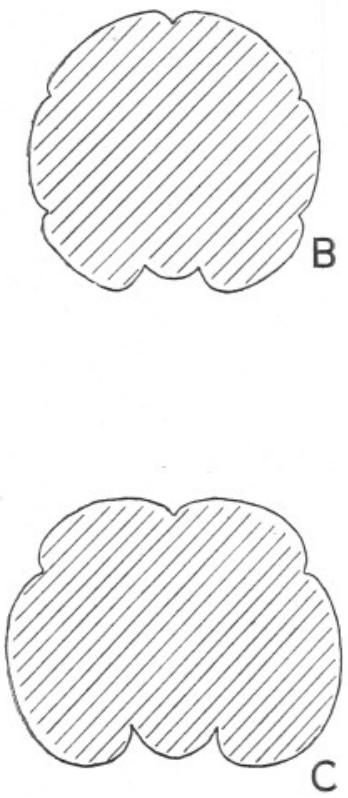

E



D
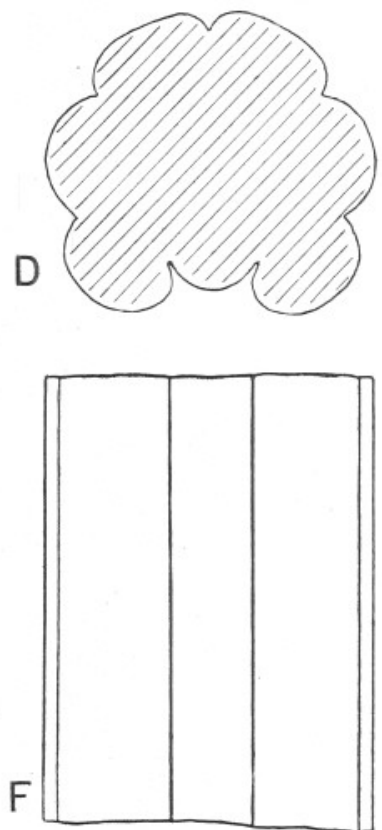

Frg. 4.-All $\times 200$. A, Pellet of Nucula tenuis, end view: B, Pellet of Nucula nitida, end view: C, Pellet of Nucula nitida, radiate form, end view: D, Pellet of Nucula nucleus, end view: E, Pellet of Nucula sulcata, end view : F, Pellet of Nucula nucleus, plan of lower surface.

Nucula sulcata.* Fig. 4, E.

Nine longitudinal ridges, separated by grooves of medium depth; the ventral ridge deeply sunk as in Nucula nucleus.

* Although occurring on this ground, no fresh specimens were available, and the above description and figure are from a single specimen supplied by Mr. A. C. Stephen from the east coast of Scotland. 


\section{Pecten septemradiatus. Fig. 5, A.}

This also voids its pellets in the form of a long rod, but the surface is less smooth than in Nucula, and frequently marked by transverse clefts so that the pellet breaks into short lengths. In section the pellet is triangular with rounded corners, one being usually sharper than the other two, and with slightly concave sides. From a specimen $3.5 \mathrm{~cm}$. across the shell the pellets are about $0.6 \mathrm{~mm}$. broad and in lengths of one to three millimetres or more.

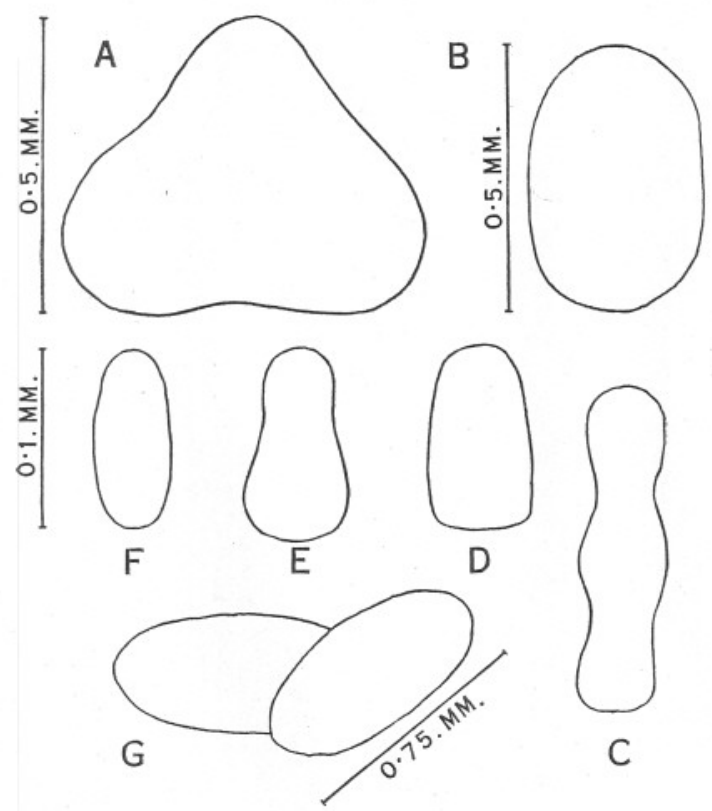

Fig. 5.-A, Pellet of Pecten septemradiatus, end view : B, Pellet of Syndosmya alba, seen from above: C, D, and E, Pellets of Syndosmya nitida, to same scale as B : F, Pellet of young Maldanid worm : G, Pellets of Maldanid-Rhodine sp.

Syndosmya alba. Fig. 5, B ; and Fig. 1.

The pellets are extremely uniform in shape, parallel-sided with rounded ends and circular in section; the surface is smooth and regular; the usual breadth is $0 \cdot 25$ to $0 \cdot 3 \mathrm{~mm}$., and the ratio of length to breadth about $1 \cdot 75$.

Syndosmya nitida. Fig. 5, C, D, and E; and Fig. 2.

Much less regular in form than S. alba, and frequently either tapered at one end or constricted at one or more points; surface smooth; narrower than $S$. alba, breadth 0.2 to $0.25 \mathrm{~mm}$. 
Maldanids, various. Fig. 5, F and $\mathrm{G}$.

There is a type of pellet very common in the mud, and not referable to any one species; this is an elongated, oval pellet quite distinct in shape from that of $S$. alba, and of from $0.1 \mathrm{~mm}$. to $2.0 \mathrm{~mm}$. in length. Two examples are shown in Fig. 5, F, being that of a young unidentified Maldanid

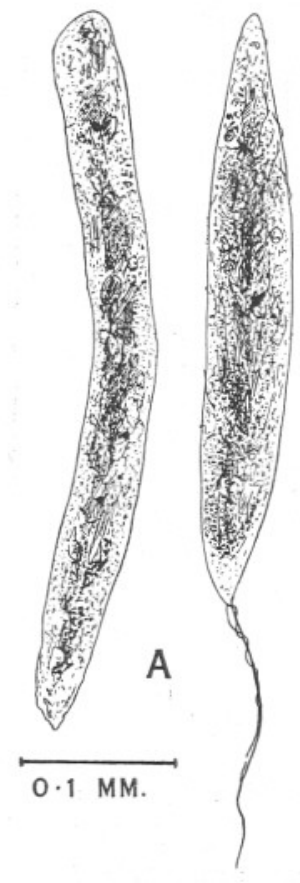

Fig. 6.-A, Pellets of Calanus finmarchicus: B, Pellets of Meganyctiphanes norvegica.

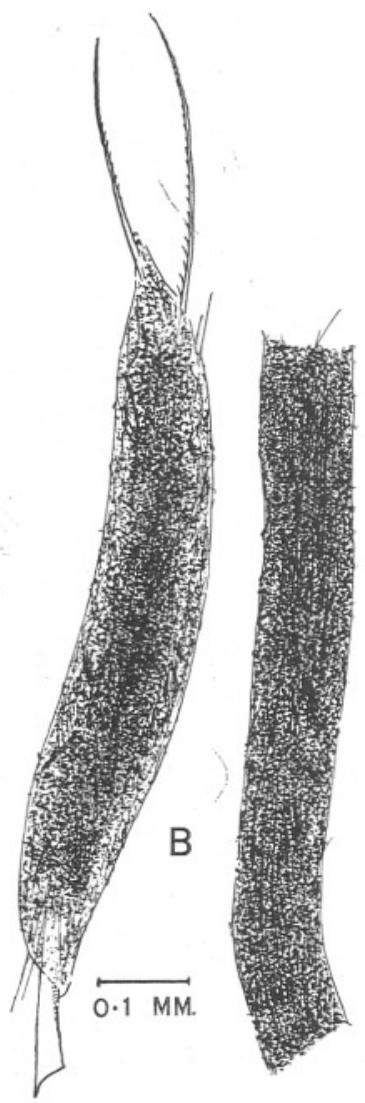

about $4 \mathrm{~mm}$. long common in the mud, and Fig. 5 , G, a pellet $0.85 \mathrm{~mm}$. long from the gut of a specimen of Rhodine sp. about $10 \mathrm{~cm}$. long.

Of the planktonic forms whose pellets may be found on the mud, Calanus is the most abundant; Sagitta, though very abundant, appears not to form a solid pellet. Euphausids, and to a lesser extent Mysids and Crangonids, are common near the bottom, but it is only possible to describe a single type of pellet common to all three. 
Calanus finmarchicus. Fig. 6, A.

This has a rather transparent pellet usually 0.05 to $0.1 \mathrm{~mm}$. in breadth and 0.2 to $0 \cdot 4 \mathrm{~mm}$. long. They vary considerably in shape, but are always elongate. The ends may be broken off, but one or both is often rounded or pointed, and one often drawn out into a long clear " tail " (Fig. 6, A). The constitution of the pellets has been described by Marshall (3) who shows that it is largely composed of diatoms and other plankton organisms, including a certain amount of crustacean fragments. The pellet is usually most transparent towards either end.

Euphausids. Fig. 6, B-i.e. Meganyctiphanes norvegica, Nyctiphanes couchii, and Thysanoessa raschii.

These have pellets somewhat similar to those of Calanus, but larger and more opaque; the ends are sometimes rounded, but they are generally broken off and frayed; crustacean remains are frequent (Macdonald, 2), and large crustacean spines often project from either end of the pellet. They vary greatly in size, those of a $30 \mathrm{~mm}$. Meganyctiphanes being about 0.1 to $0.15 \mathrm{~mm}$. broad and up to $4 \mathrm{~mm}$. long, though pellets collected on the bottom have always been found to be shorter than those shed in captivity. The above description applies also to the pellets of those Mysids and Crangonids occurring on this ground.

\section{REFERENCES.}

1. Dodgson, R. W. Fishery Investigations. Ser. II, Vol. X, No. 1, 1928.

2. Macdonald, R. Food and Habits of Meganyctiphanes norvegica. Journ. Mar. Biol. Assoc., N.S., Vol. XIV, No. 3, 1927.

3. Marshall, S. M. The Food of Calanus finmarchicus during 1923. Journ. Mar. Biol. Assoc., N.S., Vol. XII, No. 2, 1924.

4. Moore, H. B. The Muds of the Clyde Sea Area. I. Nitrogen and Phosphate Content. Journ. Mar. Biol. Assoc., N.S., Vol. XVI, No. 2, 1930.

5. Moore, H. B. The Muds of the Clyde Sea Area. III. Chemical and Physical Conditions; Rate and Nature of Sedimentation; and Fauna. Journ. Mar. Biol. Assoc., N.S., Vol. XVII, No. 2, 1931. 
